\title{
VARIATIONS IN HEMATOLOGICAL PROFILE DURING DIFFERENT TRIMESTERS OF PREGNANCY
}

\author{
MANISHA BAGHEL ${ }^{1}$, MANPREET SAINI ${ }^{1}$, MAMTA KANDWAL ${ }^{2}$, SUDHIR MODALA ${ }^{2 *}$ \\ ${ }^{1}$ Department of Biochemistry, Mayo Institute of Medical Sciences, Lucknow, Uttar Pradesh, India. ${ }^{2}$ Department of Physiology, Varun Arjun \\ Medical College, Shahjahanpur, Uttar Pradesh, India. Email: msudhir99@gmail.com
}

Received: 25 April 2020, Revised and Accepted: 08 June 2020

\section{ABSTRACT}

Objectives: The present study was aimed to determine the hematological parameters in pregnant women during different trimesters.

Methods: This is the case-control study, conducted to assess and compare the hematological profile among 120 pregnant (each trimester $\mathrm{n}=40$ ) and 40 non-pregnant women attending the obstetrics and gynecology department, Santosh Medical College and Hospital, National Capital Region Delhi. SPSS software 17.0 was used for data statistical analysis. Unpaired Student's t-test used to compare various hematological parameters between different trimesters of pregnancy and non-pregnant females. It is considered that $\mathrm{p}<0.05$ is statistically significant. Analysis of variance with a post hoc test was used.

Results: It has been observed in this study that significant differences found in parameters such as systolic blood pressure (SBP), pulse pressure (PP), heart rate, white blood cell (WBC), hematocrit (HCT), Hb\%, mean corpuscular volume (MCV), mean corpuscular hemoglobin (Hb) (MCH), and MCH concentration (MCHC). Significant differences in mean hematological values in between the trimesters $(p<0.05): 1^{\text {st }}$ trimester $(\mathrm{WBC}, \mathrm{HB}$, and $\mathrm{HCT}), 2^{\text {nd }}$ trimester (SBP, diastolic blood pressure [DBP], PP, WBC, HB, HCT, and MCHC), and $3^{\text {rd }}$ trimester (SBP, DBP, PP, WBC, HB, HCT, MCV, MCH, and MCHC) were seen, but no significant difference in age and erythrocytes count.

Conclusion: A considerable change in some hematological values between different trimesters evaluated, also decreased Hb, HCT values, and increased leukocyte values observed in the present study. These changes suggesting that it is very important to follow up hematological parameters of pregnant females during all trimesters of pregnancy so that any late complications can be avoided.

Keywords: Hematological, Pregnancy, Trimesters.

(C) 2020 The Authors. Published by Innovare Academic Sciences Pvt Ltd. This is an open access article under the CC BY license (http://creativecommons. org/licenses/by/4. 0/) DOI: http://dx.doi.org/10.22159/ajpcr.2020.v13i8.38035

\section{INTRODUCTION}

Pregnancy is defined as a physiological condition in which generally there is no adverse effect on the health of a pregnant woman. Many hormonal, hemodynamic, and hematological changes take place during pregnancy and these all changes are natural adaptations of body. For example, during pregnancy, hemostatic changes such as an increase in total blood volume take place which later helps to overcome the complication of hemorrhage at the time of delivery [1]. Hematological parameters indicate the immunological, nutritional, and hemostatic condition of a pregnant woman and are considered as major factors affecting the pregnancy $[2,3]$. These hematological parameters for pregnant women include hematocrit (HCT), total red blood cell (RBC) count, total leukocytes count, mean corpuscular volume (MCV), mean corpuscular hemoglobin $(\mathrm{Hb})(\mathrm{MCH}), \mathrm{MCH}$ concentration (MCHC), differential leukocytes count, and platelet count [4].

During pregnancy, a slight rise in plasma renin and decrease in atrial natriuretic peptide (ANP) activity suggests that rise in plasma volume is due to an underfilled vascular system which is a result of systemic vascular dilatation and increased capacitance, instead of actual blood volume expansion, which may produce opposite hormonal changes (i.e., decrease plasma renin and increased ANP levels) [5,6]. In healthy nonpregnant females, $\mathrm{Hb} 12 \mathrm{~g} / \mathrm{dl}$ is considered as the lowest normal value. According to the World Health Organization, ideal values for Hb should be maintained at or above $11.0 \mathrm{~g} / \mathrm{dl}$, and in the second trimester should not fall below $10.5 \mathrm{~g} / \mathrm{dl}$ [7]. During pregnancy, physiological stress induced by pregnant state causes leukocytosis. White cell count may rise typically up to $6000 /$ cumm [8].
There are many studies in healthy pregnant females, which show a decrease in platelet count, specifically in the last trimester of pregnancy. This condition called "Gestational thrombocytopenia" is a result of hemodilution, increased activation, and destruction of platelets [9]. The present study aims to investigate the changes in hematological profile in pregnancy.

\section{METHODS}

This study was carried out in the Department of Biochemistry, Santosh College and Hospital, Ghaziabad (National Capital Region). Ethical approval was taken from the Institutional Ethics Committee with reg. no. F. no: SU/2015/793(9) Dated: 17/06/2015; then, a written informed consent was obtained after explaining procedures to the participants.

Females in the first, second, and third trimesters of pregnancy, coming for a routine examination in the outpatient department of obstetrics and gynecology were included in this study. Participants who have any history of alcoholism, smoking, malabsorption, and kidney-related diseases are not included and also pregnant females with any history of neural tube defect are not included in this study. Similar aged group nonpregnant females of hospital staff are taken as control. The exclusion criteria for the control group were the same as like in the pregnant group. Blood samples of $5 \mathrm{ml}$ from each participant were collected by venipuncture with a prerequisite of 8-10 h fasting. Complete blood count analyzed using an automated cell counter. This instrument works on the principle of flow cell cytometry. Statistical analysis was done by SPSS 17.0 using Window R 3.2.3 interface and p-value was obtained. Analysis of variance with post hoc test used for analyzing the correlation 
between the groups and within the group among the three trimesters with hematological indices.

\section{RESULTS}

A total of 160 participants of the lower-middle socioeconomic class were taken in this study. Table 1 shows the baseline characteristics of controls and pregnant females in all groups. When compared between controls and pregnant, no statistically significant differences in age, height, and weight were observed.

Table 2 indicates as a significant difference in leukocytes $(\mathrm{p}<0.000)$, HCT $(p<0.000), H b \%(p<0.000), \operatorname{MCV}(p<0.000), M C H ~(p<0.000)$, and MCHC $(\mathrm{p}<0.000)$, but no significant difference in erythrocytes count $(p<0.118)$ has been observed. Significant difference in leukocytes $(\mathrm{p}<0.05), \mathrm{Hb}(\mathrm{p}<0.05)$, and HCT $(\mathrm{p}<0.05)$ observed in the first, second, and third trimesters when compare to controls, but no significance in MCV ( $\mathrm{p}<0.05)$ and MCH $(\mathrm{p}<0.05)$ found on comparison between control and third trimester. However, significant difference in MCHC observed during the first, second, and third trimesters compared to controls.

\section{DISCUSSION}

The present study was conducted on pregnant females coming for a regular checkup in Santosh Medical College and Hospital. The hematological parameter in the first, second, and third trimesters of the pregnant group and age-matched controls assessed, and it has been observed that there are marked changes in the hematological profile during pregnancy. Significant difference observed in HR $(\mathrm{p}<0.000)$, systolic blood pressure (SBP) $(\mathrm{p}<0.001)$, and pulse pressure (PP) $(\mathrm{p}<0.000)$. Furthermore, a significant difference observed in SBP $(\mathrm{p}<0.05)$ and PP $(\mathrm{p}<0.05)$ between the second and third trimesters compare to the control group. Normally, in pregnant women, up to the middle of pregnancy, blood pressure falls and then rises up to the day of delivery, with final indices similar to it was at the beginning of pregnancy [10]. Arterial hypertension during pregnancy is one of the major causes of perinatal mortality and morbidity [11]. Routine monitoring of BP is important for diagnosing pre-eclampsia/ eclampsia [10] as this may lead to many complications such as brain hemorrhage in the pregnant female, premature delivery, and fetal hypoxia [12]. In the present study, we observed a rise in resting heart rate (RHR) in the first, second, and third trimesters of pregnancy as found in earlier literature. Initially, during the first trimester, RHR increases abruptly followed by a moderate rise till the end of pregnancy [13]. A significant difference in all parameters such as white blood cell $(\mathrm{p}<0.000)$, HCT $(\mathrm{p}<0.001), \mathrm{Hb} \%(\mathrm{p}<0.001)$, MCV $(\mathrm{p}<0.001)$, $\mathrm{MCH}(\mathrm{p}<0.001)$, and MCHC $(\mathrm{p}<0.001)$ observed. Erythrocyte count values $(\mathrm{p}<0.118)$ in between the first, second, and third trimesters compare to the control group do not show any statistically significant. The decrease in levels of $\mathrm{Hb}$ and HCT observed in the first, second, and third trimesters of pregnancy which is characteristic features of anemia, whereas reduced MCV shows the presence of a high number of abnormal small-sized RBCs in circulation. As per the existing literature, the increased level of serum iron and ferritin is associated with increased values of $\mathrm{MCH}$, whereas higher values of weight and TIBC are associated with lower values of $\mathrm{MCH}$. Therefore, decreased values of $\mathrm{MCH}$ were observed with iron deficiency. $\mathrm{Hb}(\mathrm{p}<0.05)$ and HCT levels $(p<0.05)$ during the first, second, and third trimesters compared with controls, significant reduction found. Earlier also it was reported by Ullah et al. that during the third trimester of pregnancy as a result of increased fetus requirement, high anemia seen [14]. James et al. also stated that during pregnancy, relative reduction in HCT may be due to increased volume of plasma which causes hemodilution, hormonal changes, increased infection rate, and some other condition that may cause iron deficiency and retention of fluid [15]. On analysis of the first, second, and third trimesters, the mean (SD) leukocytes values $4.12 \pm 0.41,5.19 \pm 0.63$, and $6.35 \pm 1.04$ were found, respectively. According to Chandra et al. [16], during pregnancy, leukocytes count increases up to the reference range 6000 cells/cumm. Pughikumo et al. [17] and Costantine [18] also reported that during pregnancy. Leukocyte values were significantly higher than non-pregnant controls. Pregnancy imposes physiologic stress on the body, implicated as a possible cause of leukocytosis, and development of fetal immunity pathways also suggested as a possible reason [19].

\section{CONCLUSION}

In the present study, it is concluded that leukocytes, Hb, and HCT values show a statistically significant difference in between trimesters $(\mathrm{p}<0.05)$, suggesting the importance of routine-based obstetric evaluation and hematological profile. All hematological parameters should be properly interpreted to recognize and avoid pregnancyrelated late complications both in mother as well in the fetus.

Table 1: Average baseline characteristics of controls and study population of pregnant females with the first, second, and third trimesters

\begin{tabular}{llllll}
\hline S. No. & Parameter & $\begin{array}{l}\text { Controls } \\
(\mathbf{n = 4 0 )}\end{array}$ & $\begin{array}{l}\text { First trimester } \\
(\mathbf{n = 4 0 )}\end{array}$ & $\begin{array}{l}\text { Second trimester } \\
(\mathbf{n = 4 0 )}\end{array}$ & $\begin{array}{l}\text { Third trimester } \\
(\mathbf{n = 4 0 )}\end{array}$ \\
\hline 1. & Age (years) & $22.25 \pm 2.45$ & $21.30 \pm 1.73$ & $22.23 \pm 1.90$ & $22.80 \pm 1.70$ \\
2. & Height (cm) & $155.17 \pm 5.81$ & $157.81 \pm 5.62$ & $155.30 \pm 6.91$ & $155.10 \pm 7.63$ \\
3. & Weight (kg) & $57.31 \pm 5.32$ & $60.21 \pm 3.90$ & $66.52 \pm 7.91$ & $67.42 \pm 6.35$ \\
4. & HR (bpm) & $79.02 \pm 2.20$ & $80.01 \pm 1.91^{*}$ & $83.35 \pm 2.64^{@}$ & $83.22 \pm 2.70^{\#}$ \\
5. & SBP (mm of Hg) & $119.98 \pm 5.96$ & $118.60 \pm 6.30$ & $122.11 \pm 3.05^{@}$ & $121.95 \pm 3.13^{\#}$ \\
6. & DBP (mm of Hg) & $77.46 \pm 4.52$ & $76.62 \pm 4.09$ & $77.45 \pm 1.96$ & 0.118 \\
7. & PP (mm of Hg) & $42.49 \pm 3.95$ & $42.06 \pm 5.51$ & $44.70 \pm 2.53^{@}$ & 0.000 \\
\hline
\end{tabular}

Data expressed as mean \pm SD. SBP: Systolic blood pressure, DBP: Diastolic blood pressure, PP: Pulse pressure, HR: Heart rate. ${ }^{*}$ Controls versus first trimester; p $<0.05$, @ controls versus second trimester; $\mathrm{p}<0.05$. ${ }^{\#}$ Controls versus third trimester; $\mathrm{p}<0.05$

Table 2: Hematological parameters in control and first, second, and third trimesters of pregnancy

\begin{tabular}{|c|c|c|c|c|c|c|}
\hline S. No. & Parameter & Controls & First trimester & Second trimester & Third trimester & p-value (ANOVA) \\
\hline 1. & WBC (cells/cumm) & $4.45 \pm 0.64$ & $4.12 \pm 0.41^{*}$ & $5.19 \pm 0.63^{@}$ & $6.35 \pm 1.04^{\#}$ & 0.000 \\
\hline 2. & RBC (cells/cumm) & $3.22 \pm 0.59$ & $3.11 \pm 0.45$ & $3.04 \pm 0.47$ & $3.19 \pm 0.46$ & 0.118 \\
\hline 3. & HCT (\%) & $39.41 \pm 2.30$ & $37.61 \pm 1.21^{*}$ & $37.31 \pm 1.52^{@}$ & $37.49 \pm 1.45^{\#}$ & 0.000 \\
\hline 4. & $\mathrm{Hb}(\mathrm{g} / \mathrm{dl})$ & $11.91 \pm 0.89$ & $10.20 \pm 1.15^{*}$ & 10.08土1.24@ & $9.62 \pm 0.88^{\#}$ & 0.000 \\
\hline 5. & MCV (fl/cell) & $123.49 \pm 22.20$ & $123.06 \pm 19.42$ & $125.65 \pm 22.12$ & $124.90 \pm 22.69^{\#}$ & 0.000 \\
\hline 6. & $\mathrm{MCH}$ (pg/cell) & $37.42 \pm 6.45$ & $33.26 \pm 5.85$ & $33.75 \pm 7.51$ & $27.25 \pm 14.41^{\#}$ & 0.000 \\
\hline 7. & $\operatorname{MCHC}(\mathrm{g} / \mathrm{dl})$ & $30.56 \pm 2.92$ & $27.14 \pm 3.31^{*}$ & $26.84 \pm 3.37 @$ & $22.09 \pm 10.07^{\#}$ & 0.000 \\
\hline
\end{tabular}

Data expressed as mean \pm SD for 40 subjects in each group. Controls versus first trimester; $\mathrm{p}<0.05$, ${ }^{\circledR}$ controls versus second trimester; $\mathrm{p}<0.05$. ${ }^{\#}$ Controls versus third trimester; p<0.05. ANOVA: Analysis of variance, WBC: White blood cell, HCT: Hematocrit, MCV: Mean corpuscular volume, MCH: Mean corpuscular hemoglobin, MCHC: Mean corpuscular hemoglobin concentration, RBC: Red blood cell 


\section{ACKNOWLEDGMENT}

We sincerely acknowledge Head of the Departments of Biochemistry and Obstetrics and Gynecology, for their continuous support during the study. We would like to express our heartiest gratitude to Dr. Jyoti Batra and Dr. Hari Krishna for mentorship and encouragement.

\section{AUTHORS' CONTRIBUTIONS}

Manisha Baghel and Sudhir Modala designed the model and the computational framework, analyzed the data, and carried out the implementation. Manpreet Saini and Mamta Kandwal performed the calculations, discussed the results, and review the final manuscript with input from all authors.

\section{CONFLICTS OF INTEREST}

Nil.

\section{AUTHORS' FUNDING}

Self.

\section{REFERENCES}

1. James DK, Steer PJ, Weiner CP, Gonik B. High Risk Pregnancy: Management Options-expert Consult. $4^{\text {th }}$ ed. Netherlands: Elsevier Health Sciences; 2010. p. 70-4

2. Banhidy F, Acs N, Puho EH, Czeizel AE. Iron deficiency anemia: Pregnancy outcomes with or without iron supplementation. Nutrition 2011;27:65-72.

3. Shaw J, Dey SK, Critchley HO, Horne AW. Current knowledge of the aetiology of human tubal ectopic pregnancy. Hum Reprod Update 2010;16:432-44.

4. Das SC, Debasish S, Sanjay S, Tushar K, Biswas S. Study of hematological parameters in pregnancy. IOSR J Dent Med Sci 2013;12:42-4.

5. Ajzenberg N, Dreyfus M, Kaplan C, Yvart J, Weill B, Tchernia G. Pregnancy-associated thrombocytopenia revisited: Assessment and follow-up of 50 cases. Blood 1998;92:4573-80.

6. Barriga $\mathrm{C}$, Rodriguez AB, Orega E. Increased phagocytic activity of polymorphonuclear leucocytes during pregnancy. Eur J Obstet Gynecol Reprod Biol 1994;57:43-6.

7. Technical Working Group on Prevention and Treatment of Severe Anaemia in Pregnancy. World Health Organization. Maternal Health and Safe Motherhood Programme. Prevention and Management of Severe Anaemia in Pregnancy : Report of a Technical Working Group, Geneva, 20-22 May 1991. Geneva, Switzerland: Technical Working Group on Prevention and Treatment of Severe Anaemia in Pregnancy; 1993.

8. Fleming AF. Hematological changes in pregnancy. Clin Obstet Gynecol 1975;2:269-83.

9. Shehlata N, Burrows RF, Kelton JG. Gestational thrombocytopenia. Clin Obstet Gynecol 1999;42:327-34.

10. Nathan HL, Duhig K, Hezelgrave NL, Chappell LC, Shennan AH. Blood pressure measurement in pregnancy. Obstet Gynaecol 2015;17:91-8.

11. Finkelstein I, Bgeginski R, Tartaruga MP, Alberton CL, Kruel LF. Heart rate and blood pressure behavior throughout pregnancy, with training in water medium. Rev Bras Med Esporte 2006;12:376-80.

12. Barrilleaux PS, Martin JN Jr. Hypertension therapy during pregnancy. Clin Obstet Gynecol 2002;45:22-34.

13. Wolfe LA, Davies GA, School of Physical and Health Education, Department of Obstetrics and Gynaecology and Physiology, Queen's University, Kingston, Ontario, Canada. Canadian guidelines for exercise in pregnancy. Clin Obstet Gynecol 2003;46:488-95.

14. Ullah MZ, Khan MI, Shah M. Prevalence of anemia in pregnant women in district Karak, Khyber Pakhtunkhwa, Pakistan. Int J Biosci 2013;3:1-7.

15. James TR, Reid HL, Mullings AM. Are published standards for haematological indices in pregnancy applicable across populations: An evaluation in healthy pregnant Jamaican women. BMC Pregnancy Childbirth 2008;8:8.

16. Chandra S, Tripathi AK, Vaish K. Physiological changes in hematological parameter during pregnancy. Indian J Hematol Blood Transfus 2012;28:144-6.

17. Pughikumo OC, Pughikumo DT, Omunakwe HE. White blood cell counts in pregenant women in port Harcourt, Nigeria. IOSR J Dent Med Sci 2015;14:1-3.

18. Costantine MM. Physiologic and pharmacokinetic changes in pregnancy. Front Pharmacol J 2014;5:65.

19. Luppi P. How immune mechanisms are affected by pregnancy. Vaccine 2003;21:3352-7. 